\section{Abnormal serum liver chemistry related to pneumoperitoneum after endoscopic submucosal dissection}

A 61-year-old man had been followed after endoscopic submucosal dissection (ESD) for early gastric cancer. In his youth, the patient had undergone total colectomy because of Crohn's disease. Surveillance esophagogastroduodenoscopy revealed metachronous early gastric cancer, so a second ESD was performed. Although gastric perforation occurred during the procedure, it was closed completely using endoclips ( $\bullet$ Fig. 1 and $\bullet 2$ ). Antibiotic therapy was started with fasting. The following day, $12 \mathrm{~h}$ after the second ESD, laboratory data included aspartate aminotransferase $225 \mathrm{U} / \mathrm{L}$ (normal range 12-32 U/L), alanine aminotransferase $201 \mathrm{U} / \mathrm{L}$ (2-38 U/L), lactate dehydrogenase $526 \mathrm{U} / \mathrm{L}(119-229 \mathrm{U} / \mathrm{L})$, creatine phosphokinase $512 \mathrm{U} / \mathrm{L}(40-218 \mathrm{U} / \mathrm{L}), \mathrm{C}-$ reactive protein $3.47 \mathrm{mg} / \mathrm{dl}(<0.3 \mathrm{mg} / \mathrm{dl})$, and white blood cell count $27.75 \times 10^{3} / \mathrm{L}$ $\left(3.4-9.4 \times 10^{3} / \mathrm{L}\right)$. As electrocardiography and troponin test ruled out ischemic heart disease, an effect of pneumoperitoneum was strongly suspected. An abdominal CT scan showed severe pneumoperitoneum with compression of the inferior vena cava ( $\bullet$ Fig.3), and therefore abdominal decompression with a 14-gauge puncture needle was performed. Immediately after the puncture, the abdominal fullness and back pain improved. Four days later, almost all of the laboratory parameters recovered to within the normal ranges, and the patient made an uneventful recovery during the 14 months of follow-up after the procedure.

Gastric perforation is a major complication of endoscopic treatment, but most perforations are small and can be managed endoscopically using endoclips $[1,2]$. After endoscopic closure, if severe abdominal fullness persists, needle puncture is performed for decompression of the pneumoperitoneum in order to prevent negative systemic effects. It has been reported that prolonged pneumoperitoneum increases main arterial blood pressure and systemic vascular resistance but decreases stroke volume and cardiac output during laparoscopic surgery with carbon dioxide insufflation $[3,4]$. In our patient, abdominal CT scan revealed compression of the inferior vena cava, sug-

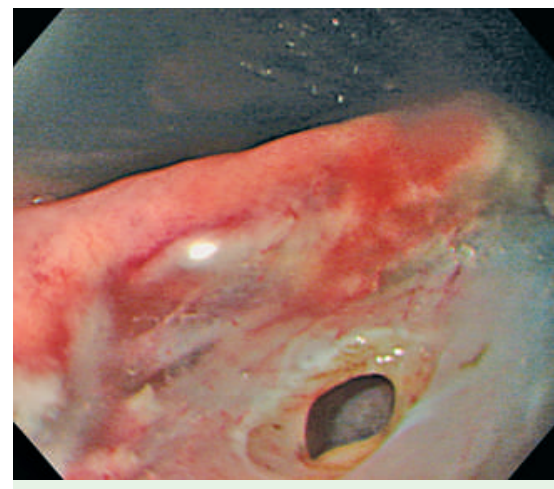

Fig. 1 Gastric perforation occurred during ESD.

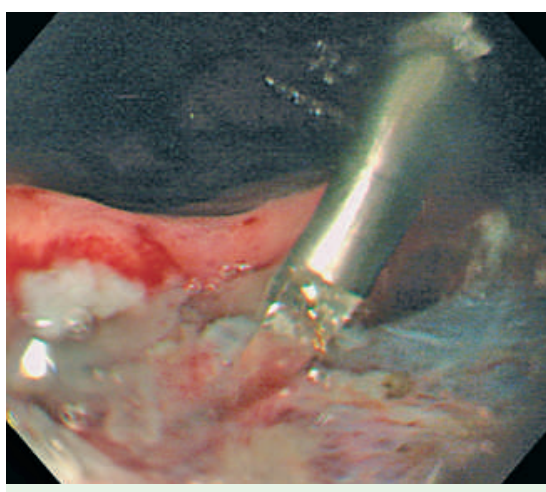

Fig. 2 Endoscopic closure was performed using an endoclip.

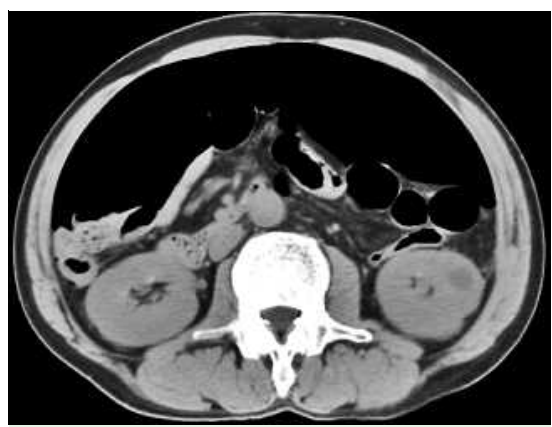

Fig. 3 Abdominal CT scan showed severe pneumoperitoneum and compression of the inferior vena cava.

gesting high intra-abdominal pressure. In this condition, we believe that the increased main arterial blood pressure and systemic vascular resistance caused congestion of the liver, resulting in elevation of liver enzyme levels [5].

\section{Acknowledgment}

\section{$\checkmark$}

This work was supported in part by a Grant-in-Aid for Cancer Research (18S-2) from the Ministry of Health, Labour and Welfare.

Endoscopy_UCTN_Code_CPL_1AH_2AZ

N. Kobayashi ${ }^{1}$, T. Ishikawa ${ }^{1}$, K.-I. Fu ${ }^{2}$,

T. Yamamoto ${ }^{1}$, Y. Hirahara ${ }^{1}$,

\section{R. Sekiguchi ${ }^{1}$}

Department of Diagnostic Imaging, Tochigi Cancer Center, Tochigi, Japan

2 Department of Radiology, Dokkyo University School of Medicine, Tochigi, Japan

\section{References}

1 Minami S, Gotoda T, Ono H et al. Complete endoscopic closure of gastric perforation induced by endoscopic resection of early gastric cancer using endoclips can prevent surgery (with video). Gastrointest Endosc 2006; 63: 596-601

2 Oda I, Gotoda T, Hamanaka $\mathrm{H}$ et al. Endoscopic submucosal dissection for early gastric cancer: technical feasibility, operation time and complications from a large consecutive series. Dig Endosc 2005; 17: 54- 58

3 Koivusalo AM, Lindgren L. Effects of carbon dioxide pneumoperitoneum for laparoscopic cholecystectomy. Acta Anaesthesiol Scand 2000; 44: 834-841

4 McLaughlin JG, Scheeres DE, Dean RJ et al. The adverse hemodynamic effects of laparoscopic cholecystectomy. Surg Endosc 1995; 9: 121 - 124

5 Meierhenrich R, Gauss A, Vandenesch P et al. The effects of intraabdominally insufflated carbon dioxide on hepatic blood flow during laparoscopic surgery assessed by transesophageal echocardiography. Anesth Analg 2005; 100: 340-347

Bibliography

DOI 10.1055/s-2007-966818

Endoscopy 2007; 39: E327

(c) Georg Thieme Verlag KG Stuttgart · New York ISSN 0013-726X

Corresponding author

N. Kobayashi, MD

Department of Diagnostic Imaging

Tochigi Cancer Center

320-0834 Yonan

Utsunomiya

Tochigi

Japan

Fax: +81-28-6585488

nkobayas@tcc.pref.tochigi.jp

\section{H}

